\title{
Paramedics, technicians, and survival from out of hospital cardiac arrest
}

\author{
Timothy H Rainer, Ruth Marshall, Stephen Cusack
}

\begin{abstract}
Objective-To test the hypothesis that limited paramedic advanced life support skills afford no advantage in survival from cardiac arrest when compared with nonparamedic ambulance crews equipped with defibrillators in an urban environment; and to investigate whether separate response units delayed on scene times. Methods-A prospective, observational study was conducted over 17 consecutive months on all adult patients brought to the accident and emergency (A\&E) department of Glasgow Royal Infirmary having suffered an out of hospital cardiac arrest of cardiac aetiology. The main interventions were bystander cardiopulmonary resuscitation (CPR) and limited advance life support skills.
\end{abstract}

Main outcome measures-Return of spontaneous circulation, survival to admission, and discharge.

Results-Of 240 patients brought to the A\&E department, 19 had no clear record of whether a paramedic was or was not involved and so were excluded. There was no difference in survival between the two groups, although a trend to admission favoured non-paramedics. Paramedics spent much longer at the scene $(P<$ $0.0001)$. Witnessed arrests $(P=0.01)$, early bystander CPR $(P=0.12)$, shockable rhythms $(P=0.003)$, and defibrillation $(P$ $<0.0001$ ) were associated with better survival. Intubation and at scene times were not associated with better survival. Delayed second response units did not prolong at scene times.

Conclusions-The interventions of greatest benefit in out of hospital cardiac arrest are basic life support and defibrillation. Additional skills are of questionable benefit and may detract from those of greatest benefit.

$(F$ Accid Emerg Med 1997;14:278-282)

Keywords: emergency medical system; cardiac arrest; paramedics; survival

In the United States during the third quarter of this century there was a perceived need to provide early, effective, emergency care in the community. One means of achieving this was through the introduction of paramedicsambulance personnel trained to provide advanced life support. During the 1970 s several studies reported that paramedics improved outcomes when compared with technicians. ${ }^{1-4}$
Others have reported that this is a costeffective means of providing care..$^{5-7}$ Consequently, it is government policy in the United Kingdom to man each front line ambulance with a paramedic. ${ }^{89}$ However, the claim that this is an efficient, effective means of providing prehospital care to our communities has been contested. ${ }^{1011}$

We tested the hypothesis that there is no difference in survival following out of hospital cardiac arrest between paramedics and technicians equipped with defibrillators in Glasgow, and also studied the effect of arrival times between the groups on at scene time.

DESCRIPTION OF EMERGENCY MEDICAL SERVICES IN GLASGOW

Three types of front line emergency response existed during the period of the studyambulances manned only by technicians equipped and trained in the use of advisory defibrillators (EMT-Ds); ambulances manned by a technician and a paramedic; and single man paramedic response units. Technicians were all trained and equipped to perform basic life support and defibrillation (EMT-Ds). Paramedic skills include peripheral intravenous cannulation, clear fluid administration, endotracheal intubation, and the administration of selected drugs. During the period of this study, paramedics did not carry drugs.

The city of Glasgow has a population of 700000 , and is served by four hospitals, each with an accident and emergency (A\&E) department. The total new patient attendance to $A \& E$ departments in Glasgow is 210000 . One of these hospitals-Glasgow Royal Infirmary - is a teaching hospital situated in the relatively deprived east end of the city. The catchment population for the emergency services delivering patients to this hospital is approximately 200000 (male to female ratio, $0.91: 1.0$ ) from a geographical area of approximately 40 square miles. Glasgow Royal Infirmary has 900 acute beds and an A\&E department which receives 75000 new patients per annum. The standardised mortality ratios (SMR) for ischaemic heart disease (IHD, ICD-9: 410-414) in Glasgow City when compared with Scotland were: for males, 425.5 (1993) and 381.3 (1994); and for females, 330.5 (1993) and 300.3 (1994). ${ }^{1213}$ SMRs for the section of Glasgow served by this $A \& E$ department are not available. However, it is one of the more deprived areas of the city and SMRs may well be greater than for the city as a whole. 


\begin{abstract}
Methods
STUDY DESIGN

This prospective, single centre, longitudinal, observational study covered the period from 1 January 1993 to 31 May 1994. All adult patients with non-traumatic cardiac arrests of presumed cardiac aetiology occurring outside hospital and brought to the A\&E department were included. Children ( $<13$ years of age), those pronounced dead on arrival, suicide, exsanguination, hypoxia, cerebrovascular accidents and subarachnoid haemorrhages, poisoning, near drowning, and pregnancy were excluded from analysis.
\end{abstract}

\section{DEFINITIONS AND DATA}

The definition of cardiac arrest is that used by the Resuscitation Council (UK). ${ }^{14}$ European Resuscitation Council guidelines for the resuscitation of adult cardiac arrest were followed. ${ }^{15}$ Data were collected from ambulance personnel within $A \& E$ at the time of delivery of the patient, and also from the patient report form which all ambulance personnel are required to complete at the same time. Data recorded were in accordance with the Utstein style and a summary of definitions is given in table $1 .{ }^{16}$ No attempt has been made to discriminate between subjects arresting in the presence or absence of ambulance crews.

FOLLOW UP AND OUTCOME

The primary measures were return of spontaneous circulation, admission to a hospital ward including intensive care or coronary care units, and discharge from hospital. Secondary outcome measures were prehospital times.

Table 1 Interval definitions

\begin{tabular}{ll}
\hline Collapse-call time & Collapse of the patient to reception of the call at ambulance control \\
\hline Call-response time & $\begin{array}{l}\text { Reception of the call at ambulance control to the time when the } \\
\text { ambulance stops at the scene } \\
\text { Time when the ambulance stops at the scene to the time when it } \\
\text { departs from the scene } \\
\text { Time from departure from scene to arrival at the hospital } \\
\text { At scene time }\end{array}$ \\
$\begin{array}{l}\text { Total time interval from collapse of the patient to end of CPR or to } \\
\text { dispatch from resuscitation room }\end{array}$ \\
Resuscitation & $\begin{array}{l}\text { Time from when the ambulance stops at the scene to delivery of } \\
\text { the first } 200 \mathrm{~J} \text { dc shock }\end{array}$ \\
Arrival-defibrillation time
\end{tabular}

CPR, cardiopulmonary resuscitation.

Table 2 Comparison of characteristics and primary outcomes for out of hospital cardiac arrests between paramedics and technicians using the "Utstein style" template for reporting (catchment population $=200000)$

\begin{tabular}{lllll}
\hline Characteristic & $\begin{array}{l}\text { Data } \\
\text { availability }\end{array}$ & $\begin{array}{l}\text { Paramedics } \\
(n=111)\end{array}$ & $\begin{array}{l}\text { EMT-Ds } \\
(n=110)\end{array}$ & P value \\
\hline $\begin{array}{l}\text { Male sex, No (\%) } \\
\text { Age, years }\end{array}$ & $78(70)$ & $88(80)$ & \\
$\quad$ Median & & 65.5 & 66.5 & \\
$\quad$ Range & & 17 to 83 & 22 to 89 & \\
$\quad$ IQR & & 58,73 & 45,74 & \\
Witnessed, No (\%) & $188(85) \dagger$ & $71(64)$ & $74(67)$ & 0.80 \\
VF/VT, No (\%) & $190(86) \dagger$ & $33(30)$ & $37(34)$ & 0.43 \\
Bystander CPR, No (\%) & $181(82) \dagger$ & $35(32)$ & $30(27)$ & 0.29 \\
Primary outcomes & & & & \\
Died before admission & $59(24) \dagger$ & $26(23)$ & $38(71)$ & \\
ROSC, No (\%) & & $17(15)$ & $25(23)$ & 0.34 \\
Admitted to ICU/CCU, No (\%) & & $8(7)$ & $6(6)$ & 0.16 \\
Discharged, No (\%) & & & \\
\hline
\end{tabular}

† The number of patients for whom data was available, specified only for variables with missing data.

* $I Q R$, interquartile range.

VF/VT, ventricular fibrillation/ventricular tachycardia; CPR, cardiopulmonary resuscitation ROSC, return of spontaneous circulation; ICU, intensive care unit; CCU, coronary care unit.
STATISTICAL METHODS

Summary descriptive statistics are presented, in keeping with the Utstein recommendations for reporting non-parametric data using medians and ranges. Patient characteristics and primary outcome measures were analysed using $\chi^{2}$ tests to test the hypothesis that there was no statistical difference between the two study groups. Continuous time variables were analysed using two sample $t$ tests assuming unequal variances, and all $P$ values are two tailed. In order to assess the significance and power of individual datasets, results are presented as means with $95 \%$ confidence intervals.

\section{Results}

During the 17 month study, 240 consecutive patients with cardiac arrest of presumed cardiac aetiology were brought to the $A \& E$ department of Glasgow Royal Infirmary by the Emergency Services. In 19 there was no information describing whether they were seen by a paramedic and/or an EMT-D crew. These were excluded, leaving 221 cases for analysis.

\section{PATIENT CHARACTERISTICS AND PRIMARY}

OUTCOME MEASURES

Age and sex distribution, initial patient variables and primary outcome measures are presented in table 2 . There was no statistical difference between paramedics and EMT-Ds in the proportions of subjects with witnessed arrests, those found to be in ventricular fibrillation/ventricular tachycardia (VF/VT) on arrival of the EMS, and those receiving bystander cardiopulmonary resuscitation (CPR). The EMT-D group had a greater proportion of patients with VF/VT as the presenting rhythm than the paramedic group $(42 \% v 35 \%)$. However, the EMT-D group contained fewer patients receiving bystander CPR on arrival (33\% v 40\%).

There was variability in completion of individual items of information, ranging from $24 \%$ to $100 \%$. No significant difference was observed in any primary outcome measure between the two EMS groups. There appeared to be a trend favouring EMT-Ds for those with return of spontaneous circulation $(29 \% v$ $23 \%)$ and for those admitted to hospital (23\% $v 15 \%)$. Numbers were small but more patients were discharged by paramedics than by EMT-Ds $(7 \% v 6 \%)$.

The impact of each intervention upon survival to admission is presented in table 3. A witnessed arrest, VF/VT as the initial arrest rhythm, and defibrillation correlated with better outcomes. Neither bystander CPR nor endotracheal intubation favoured survival, but there was a trend favouring survival to admission in the former.

\section{TIME INTERVALS}

Data collection for individual time intervals varied from $38 \%$ to $78 \%$ (table 4 ). Paramedics spent longer at the scene, were slower to return to the base hospital than EMT-Ds, and were slower to defibrillate. 
Table 3 Survival of patients to hospital ward admission

\begin{tabular}{|c|c|c|c|}
\hline Variable & Died & Admitted & Pvalue \\
\hline \multicolumn{4}{|l|}{ Witnessed } \\
\hline Yes & 113 & 35 & \\
\hline No & 43 & 31 & 0.01 \\
\hline \multicolumn{4}{|l|}{ Bystander CPR } \\
\hline Yes & 51 & 17 & \\
\hline No & 101 & 19 & 0.12 \\
\hline \multicolumn{4}{|l|}{ VF/VT } \\
\hline Yes & 54 & 20 & \\
\hline No & 114 & 14 & 0.003 \\
\hline \multicolumn{4}{|l|}{ Defibrillation } \\
\hline .Yes & 80 & 35 & \\
\hline No & 89 & 8 & $<0.0001$ \\
\hline \multicolumn{4}{|l|}{ Intubation } \\
\hline Yes & 74 & 13 & \\
\hline No & 92 & 28 & 0.14 \\
\hline \multicolumn{4}{|c|}{ On scene time (minutes) } \\
\hline Median & 14 & 16 & \\
\hline Range & 3 to 26 & 3 to 46 & \\
\hline Mean $(95 \% \mathrm{CI})$ & $14.31(12.27$ to 16.35$)$ & $17.19(15.88 \text { to } 18.5)^{\star}$ & \\
\hline
\end{tabular}

$\mathrm{CI}$, confidence interval in relation to the mean; CPR, cardiopulmonary resuscitation; VF/VT, ventricular fibrillation/ventricular tachycardia.

${ }^{\star} \mathrm{P}=0.016$.

In the paramedic cohort there was always another crew member at the scene, either as part of the same front line ambulance crew or from a separate crew to transport the patient to hospital. Arrival times were available for $50 \%$ of these cases (table 5). In 33 case events $(60 \%)$ the paramedic arrived at the same time as the EMT-D crew. The paramedic arrived before an EMT-D crew in only two cases (4\%) and in both of these the second response unit arrived within two minutes of the first. In 20 cases $(36 \%)$ an EMT-D crew preceded a paramedic to the scene. Of these in only five cases was the delay greater than five minutes (table 6).

\section{Discussion}

The results of this study are similar to that of Guly et al in Edinburgh. ${ }^{10}$ They suggest that paramedics equipped with a limited range of advanced life support skills do not improve survival when compared with EMT-Ds. Our data indicate that current paramedic training in the United Kingdom may not improve survival in urban communities. The skills that paramedics currently use may distract from skills of proven efficacy-basic life support and defibrillation. ${ }^{15} 17$

Our study suggests that paramedics spend much longer at the scene and that this is not reflected in better outcome to return of spontaneous circulation or hospital admission. In the majority of cases paramedics arrived at the same time as EMT-Ds. This group probably represents a front line ambulance manned by a paramedic, although we cannot exclude the small possibility that a separate crew and paramedic arrived at the scene simultaneously. Paramedics functioned as a second response unit in only a few cases, suggesting that such delays did not account for prolonged on scene times.

A witnessed arrest and a shockable rhythm are shown to improve survival to admission to a hospital ward. While we did not confirm statistically that bystander CPR improved survival, there were trends favouring basic life support, and many others have demonstrated its importance. ${ }^{18}$ Defibrillation remains an intervention of immense importance, but endotracheal intubation is not associated with improved survival. Others, however, have shown an improvement in survival with endotracheal intubation in defibrillated patients when compared with basic life support. ${ }^{19}$

This study suggests that where two highly motivated groups-paramedics and EMTDs-exercise their respective skills at the scene of an arrest, those with more to do will spend longer. EMS personnel often function in adverse circumstances with poor lighting, limited and cramped operational space, and a small crew. Good basic life support and defibrillation will take most of their effort. The placement of intravenous lines has been shown, albeit retrospectively, to prolong on scene times without improving the chances of patients receiving effective treatment. ${ }^{20} \mathrm{We}$ found a greater delay to defibrillation in the paramedic group, although this did not reach statistical significance.

As paramedics at the time of this study had only limited advanced life support skills, it may be argued that they are disadvantaged by these limitations. Our study was limited to a period when paramedics gave no drugs and so we cannot address this issue. Others have questioned the value of drug administration. ${ }^{1121}$ The placement of intravenous lines in the context of cardiac arrest is therefore of questionable value.

Some reports from the United Kingdom have shown better survival from cardiac arrest in those treated by paramedics when compared with technicians. ${ }^{22}{ }^{23}$ One did not clearly differentiate those who were equipped with full advanced life support skills from those who had only access to a defibrillator. ${ }^{22}$ In another, ${ }^{23}$ EMT-Ds appeared to provide little improve-

Table 4 Time intervals in minutes

\begin{tabular}{|c|c|c|c|c|c|c|c|c|c|}
\hline \multirow[b]{3}{*}{ Interval variable } & \multicolumn{4}{|c|}{ Paramedics $(n=111)$} & \multicolumn{4}{|c|}{$E M T-D s(n=110)$} & \multirow[b]{3}{*}{ P value } \\
\hline & \multirow[b]{2}{*}{ No $(\%)^{*}$} & \multicolumn{3}{|l|}{ Time } & \multirow[b]{2}{*}{ No $(\%)^{*}$} & \multicolumn{3}{|l|}{ Time } & \\
\hline & & Median (range) & Mean & $95 \% C I$ & & Median (range) & Mean & $95 \% C I$ & \\
\hline $\begin{array}{l}\text { Collapse-call time } \\
\text { Call-response time } \\
\text { At scene time } \\
\text { Return time } \\
\text { Resuscitation time } \\
\text { Arrival to defibrillation } †\end{array}$ & $\begin{array}{l}44(40) \\
86(78) \\
81(73) \\
80(72) \\
50(45) \\
29(54)\end{array}$ & $\begin{array}{l}2(0 \text { to } 35) \\
8(0 \text { to } 20) \\
18(0 \text { to } 46) \\
6(0 \text { to } 20) \\
47(23 \text { to } 128) \\
3(1 \text { to } 40)\end{array}$ & \begin{tabular}{l|l|}
3.98 \\
8.69 \\
18.91 \\
6.93 \\
53.36 \\
8.72
\end{tabular} & $\begin{array}{l}2.15 \text { to } 5.81 \\
7.84 \text { to } 9.54 \\
17.57 \text { to } 20.25 \\
5.87 \text { to } 7.99 \\
47.7 \text { to } 58.93 \\
4.54 \text { to } 12.90\end{array}$ & $\begin{array}{l}42(38) \\
70(64) \\
61(56) \\
61(56) \\
38(35) \\
29(58)\end{array}$ & $\begin{array}{l}3(0 \text { to } 31) \\
6.5(0 \text { to } 21) \\
14(2 \text { to } 28) \\
5(0 \text { to } 15) \\
45(23 \text { to } 141) \\
3(0 \text { to } 32)\end{array}$ & \begin{tabular}{l|l|}
4.88 \\
7.22 \\
13.18 \\
5.77 \\
52.53 \\
4.73
\end{tabular} & $\begin{array}{l}2.94 \text { to } 6.82 \\
6.30 \text { to } 8.14 \\
11.78 \text { to } 14.58 \\
4.90 \text { to } 6.64 \\
44.31 \text { to } 60.75 \\
2.54 \text { to } 6.92\end{array}$ & $\begin{array}{l}0.51 \\
0.22 \\
<0.0001 \\
0.10 \\
0.39 \\
0.11\end{array}$ \\
\hline
\end{tabular}

$\mathrm{CI}$, confidence interval in relation to the mean.

† Data availability has the number of VF/VT arrests as the denominator, $n=50$ for EMT-D and $n=54$ for paramedics.

* The number of patients for whom data was available, specifed because of the variation in pick up rate for individual datasets. 
Table 5 Comparison of response times (in minutes) of paramedics and EMT-Ds when both responded to the same patient $($ No $=111)$

\begin{tabular}{lll}
\hline Response & Paramedics & EMT-Ds \\
\hline $\begin{array}{ll}\text { Call to arrival } \\
\text { of EMT, }\end{array}$ & & \\
No (\%) & $55(50)$ & $57(53)$ \\
Median & 10 & 8.5 \\
Range & 3 to 25 & 1 to 22 \\
Mean & & $9.29(8.24 \text { to } 10.34)^{\star}$ \\
$(95 \%$ CI $)$ & $10.44(9.25$ to 11.63$)$ & 9
\end{tabular}

$\mathrm{CI}$, confidence interval in relation to the mean. $\star \mathrm{P}=0.15$.

Table 6 Differences in arrival times between paramedics and technicians when both responded to a call

\begin{tabular}{ll}
\hline Arrival & $\begin{array}{l}\text { Number of cases } \\
\text { events }\end{array}$ \\
\hline Simultaneous response & $33(60 \%)$ \\
Paramedic first $\dagger$ & $2(4 \%)$ \\
Crew first & $20(36 \%)$ \\
Crew preceded paramedic by & 5 \\
1 minute & 10 \\
3-5 minutes & 5
\end{tabular}

† The paramedic was delayed while waiting for a transporting crew by only two minutes in both cases.

ment in survival when compared with crews not equipped with defibrillators. This finding is strange in view of the recognised benefit of defibrillation in survival from cardiac arrest. ${ }^{15}$ Neither reported in the Utstein style, so we do not know whether their results are comparable with ours.

In our study we pay no attention to premorbid status or postresuscitation care, although there is no reason to believe that one group should be favoured at the expense of the other. Our study is further limited in that the east end of Glasgow has particularly poor survival rates following cardiac arrest, a high proportion of subjects in asystole as a presenting rhythm when the ambulance first arrives, and a low level of bystander CPR. ${ }^{24}$ Under such circumstances, demonstrating improvements in outcome is particularly difficult. The failure to show that bystander CPR significantly improves outcome suggests that the power of the study is low. We estimate that the actual power is less than $50 \%$. On the basis of our overall survival figures to admission, we calculate that a minimum of 768 patients would be required to show with greater than $95 \%$ probability and to a power of $80 \%$ that there is a significant difference between the two cohorts. To establish a significance difference in survival to discharge would require 191970 case events equally divided between the two groups.

Although Guly's study received a number of criticisms, ${ }^{232526}$ our study appears to augment their findings. It is essential that investigators report on survival outcomes in a standard style, either confirming or contradicting the findings from Edinburgh and Glasgow. If our results are confirmed then the lack of demonstrable improvement in survival by paramedics should be addressed. The overwhelming need in the response to cardiac arrest in the community is the provision of basic life support and defibrillation. The value of other advanced life support interventions remains at best minimal and at worst detrimental. If it takes a minimum of two to three people to perform good basic life support and defibrillation, the use of other advanced life support skills requires a larger team. Either we need larger teams or serious consideration needs to be given to the preparation of guidelines for prehospital personnel that emphasise cycles of basic life support and defibrillation, and exclude the other advanced life support interventions.

\section{CONCLUSIONS}

This study shows that in the emergency response to cardiac arrest in an urban community, the skills provided by paramedics have little advantage over those of EMT-Ds. We believe that the early improvements in survival by paramedics compared to EMTs are explained by the fact that the latter were not equipped with defibrillators, rather than other aspects of definitive care. The importance of witnessed arrests, early CPR, presenting rhythm, and defibrillation cannot be overemphasised. We question the value of other advanced life support skills in the management of cardiac arrest and whether paramedics have a role to play in this area.

We thank Mr I J Swann for the opportunity of studying patients brought to his department.

1 Eisenberg MS, Horwood BT, Cummins RO, ReynoldsHaertle R, Hearne TR. Cardiac arrest and resuscitation: a tale of 29 cities. Ann Emerg Med 1990;19:179-86.

2 Eisenberg MS, Copass MK, Hallstrom A, Cobb LA, Eisenberg MS, Copass MK, Hallstrom A, Cobb LA, Bergner $L$. Management of out-of-hospital cardiac arrest.
Failure of basic emergency technician services. JAMA 1980;243:1049-51.

3 Eisenberg MS, Bergner L, Hallstrom A. Paramedic programs and out-of-hospital cardiac arrest: I. Factors associated with successful resuscitation. Am J Public Health $1979 ; 69: 30-8$.

4 Eisenberg MS, Bergner L, Hallstrom A. Paramedic programs and out-of-hospital cardiac arrest: II. Impact on community mortality. Am J Public Health. 1979;69:39-42.

5 Urban N, Bergner L, Eisenberg MS. The costs of a suburban paramedic program in reducing deaths due to cardiac arrest. Med Care 1982;19:379-92.

6 Valenzuela TD, Criss EA, Spaite D, Meislin HW, Wright AL, Clark L. Cost-effectiveness analysis of paramedic emergency medical services in the treatment of prehospital cardiopulmonary arrest. Ann Emerg Med 1990;19:140711 .

7 Bjorklund P, O'Rourke MF. Prehospital emergency care: valuation of an Australian system. Aust NZ J Med evaluation of an $A$

8 National Health Service Training Directorate. National Health Service training manual. Bristol: NHSTD, Swindon Press, 1991.

9 Department of Health. The Health of the Nation: key area handbook; accidents. London: Department of Health, 1993.

10 Guly UM, Mitchell RG, Cook R, Steedman DJ, Robertson $\mathrm{CE}$. Paramedics and technicians are equally successful at managing cardiac arrest outside hospital. BMJ 1995;310: 1091-4.

11 Goldstein DH, Mackenzie BR, Merchant N, Lalonde LD, Johnstone DE. Effectiveness of a non-amalgamated ambulance service on out-of-hospital sudden cardiac death. Can J Cardiol 1987;3:66-9.

12 Register General Scotland. Edinburgh: General Register Office, 1994.

13 Register General Scotland. Edinburgh: General Register Office, 1995.

14 Evans TR, ed. $A B C$ of resuscitation, 2nd ed. London: BM J Publishing Group, 1990

15 Advanced Life Support Working party of the European Resuscitation Council. Guidelines for advanced life supResuscitation Council. Guidelines for

16 Task force of representatives from the European Resuscitation Council, American Heart Association, Heart and tion Council, American Heart Association, Heart and Stroke Foundation of Canada, Australian Resuscitation Council. Recommended guidelines for uniform reporting of data from out-of-hospital cardiac arrest: the 'Utstein style'. Resuscitation 1991;22:1-26.

17 Sedgwick ML, Dalziel K, Watson J, Carrington DJ, Cobbe SM. Performance of an established system of first responder out-of-hospital defibrillation. The results of the second year of the Heartstart Scotland Project in the 'Utstein style.' Resuscitation 1993;26:75-88. 
18 Bossaert L, Van Hoeyweghen R. Bystander CPR in out-ofhospital arrest. Resuscitation 1989;17:S55-69.

19 Hillis M, Sinclair D, Butler G, Cain E. Prehospital cardiac arrest survival and neurological recovery. J Emerg Med 1993;11:245-52.

20 Donovan PJ, Cline DM, Whitley TW, Foster C, Outlaw M Prehospital care by EMT's and EMT-I's in a rural setting: prolongation of on scene times by ALS procedures. Ann Emerg Med 1989;18:495-500.

21 Rainer TH, Robertson CE. Adrenaline, evidence-based medicine and cardiac arrest. J Accid Emerg Med 1996;13: 234-7.
22 Jones SD, Donnelly PD, Bewley J, Weston CFM. Respiratory arrest outside hospital. Resuscitation 1995;29:107-11. 23 Weston C, Donnelly P. Studying only admissions is a source of potential bias. BMJ 1995;311:509.

24 Rainer TH, Gordon MWG, Robertson CE, Cusack S Evaluation of outcome following cardiac arrest in patient presenting to two Scottish emergency departments. Resuscitation 1995;29:33-9.

25 Marsden AK, Cobbe SM. Paramedics have other use beside attending cardiac arrests. BMJ 995;311:508.

26 Mindell J, Ward K, Ide S. Paramedics were not used effectively. BMJ 1995;311:508.

\section{Clinical Considerations in Aeromedical Transport}

A five day continuing professional development course at the Cranfield College of Aeronautics, 22-26 September 1997.

The course is designed for aeromedical escorts. It is practically based and will be taught by aviation physiology and transport medicine experts.

The five days will cover:

- Aviation physiology

- Transport medicine

- Critical care in the air

- Helicopter operations

- Fixed wing operations

- Logistics, organisation, and equipment.

Practical aspects will include a demonstration of a typical air ambulance, land and sea survival equipment, and the use of medical equipment in aircraft.

Course fee $£ 500$; residence $£ 400$. Further details from: Lesley Roff, Short Course Manager, Cranfield University, Cranfield, Bedford MK43 OAL; tel 01234 750111, ext 2562/2564; fax 01234751206. 